\title{
Efficiency Enhancement in Dye Sensitized Solar Cell Using 1D Photonic Crystal
}

M.Ismail Fathima ( $\square$ ismanus86@yahoo.com )

Arul Anandar College

K.S.Joseph wilson

Arul Anandar College

\section{Research Article}

Keywords: Photonic crystal, Absorber, Dye sensitized solar cell, Efficiency

Posted Date: February 18th, 2021

DOI: https://doi.org/10.21203/rs.3.rs-208286/v1

License: (9) This work is licensed under a Creative Commons Attribution 4.0 International License. Read Full License 


\section{Efficiency Enhancement in Dye Sensitized Solar Cell Using 1D Photonic Crystal \\ M. Ismail Fathima ${ }^{1}$ K.S. Joseph Wilson ${ }^{1^{*}}$ $P G \&$ Research Department of Physics, Arul Anandar College(Autonomous), \\ Karumathur, Madurai ,India \\ Corresponding Author:ismanus86@yahoo.com}

\section{Abstract} $1 \mathrm{D} \mathrm{SiO}_{2} / \mathrm{TiO}_{2}$ photonic crystal based $\mathrm{ZnO}$-Pt DSSC with $\mathrm{N} 719$ dye is theoretically designed. The optical properties of theoretically designed DSSC such as transmittivity, Absorptivity and reflectivity are calculated using transfer matrix method in order to calculate numerically the key parameters like open circuit voltage $\left(V_{O C}\right)$, Photo current density $\left(J_{p h}\right)$ of the DSSC. It is found that the desired integrated system may enable to maximize the absorption in the selective spectrum region (400-900nm) and hence the maximum efficiency achieved is $4.5 \%$ for a $1 \mathrm{D} \mathrm{SiO}_{2} / \mathrm{TiO}_{2}$ photonic crystal layers with two number of periods.

Key words: Photonic crystal, Absorber, Dye sensitized solar cell, Efficiency.

\section{Introduction}

Dye-sensitized solar cells (DSSCs) have emerging as a technical and economical sustainable substitute to the p-n junction photovoltaic devices. The chlorophyll-form sensitized zinc oxide electrode based DSSC was synthesized in 1972 [1]. Recently sensitized solar cells like DSSCs and quantum dot sensitized solar cells (QDSCs) are promising low-cost option to conventional photovoltaic devices based on materials such as Si and CdTe due to their lower cost and effortless fabrication process [2-3]. A Number of research has been executed on $\mathrm{ZnO}$ single crystals, even so the efficiency of these dye-sensitized solar cells were very down and out being as the monolayer of dye molecules was capable to absorb incident light intensity only around $1 \%$ [2]. Thus, optimizing the porosity of the electrode made up of refine oxide powder upgrade the efficiency of DSSC. Hence the dye absorption over electrode might be enhanced to improve the light harvesting efficiency (LHE).

Nano porous titanium dioxide DSSC with 7\% efficiency were discovered in 1991[3]. Although various studies have been reported that the absolute efficiency of $\mathrm{TiO}_{2}$ DSSCs is always higher than that of ZnO DSSCs efficiency [4]. This is because of the presence of the high carboxylic acid essential groups in the dyes in which the dissolution of $\mathrm{ZnO}$ and precipitation of dye- $\mathrm{Zn}^{2+}$ complexes occurs. This occurrence results in a deficient overall electron injection efficiency of the dye.

The overall power conversion efficiency have been focused on increase the photovoltage through function of the oxide, improving the photocurrent with new dyes, and 
boosting stability by better encapsulation [5]. By the use of liquid electrolyte in DSSCs in the spectral range around $520 \mathrm{~nm}$.

Intense research efforts largely focused on synthesizing new organic dye molecules with higher absorptivity materials as were invented more efficient carrier transport layers [6]. The photon management conception has presently plays an important research field to enhance LHE in photovoltaics. Several theoretical approaches are reported already on a variety of possible effects including the localization of heavy photons near the edges of a photonic bandgap [7], Bragg diffraction in a periodic lattice [8], multiple scattering at disordered regions in the photonic crystal (PhC) [9], and the formation of multiple resonant modes [10]. One approach to strongly strengthen the LHE is using optical elements, such as highly scattering layers. This consist of Photonic Crystal $(\mathrm{PhC})$ absorption layer with $\mathrm{ZnO}$ photo anode on DSSC that increases the photon path length in the cell [10-12].

Nanostructured materials, such as PhCs, large particle aggregation scattering layers, and plasmonic nanometals have opened to increase LHE in the third-generation solar cells [1316]. PhCs, with periodic dielectric nanostructures, view strong ability to attain a unique level of control the light propagation are also light energy distribution in photovoltaic devices [1719]. In these devices via several mechanisms, such as photon localization increase the red light absorption near the red edge of a photonic bandgap, light reflection within the photonic bandgap at various angles and formation of photon resonance modes within the solar cell are used to increase the LHE [16,17]. Hence photovoltaic devices integrated with PhCs, photons absorption increases which results increased LHE with lower usage of absorbing materials. The first verification of light absorption enhancement outcome of $\mathrm{PhC}$ coupled sensitized solar cells in 2003 has stimulated more and more efforts to design PhCs with different optical structural and properties that permit for light management in the cells [20].

In this work it is plan to investigate on theoretical design of porous nature of Zno-Pt DSSC with N719 dye. Optical properties of theoretical designed DSSCs such as transmittance, reflectance and absorptance are calculated using Transfer Matrix Method (TMM), in order to calculate numerically, the key parameters like open circuit voltage $\left(\mathrm{V}_{\mathrm{oc}}\right)$, Photo current density $\left(\mathrm{J}_{\mathrm{ph}}\right)$, efficiency etc. In addition, the efficiency of porous $1 \mathrm{D} \mathrm{SiO} / \mathrm{TiO}_{2} \mathrm{PhC}$ coupled $\mathrm{ZnO}-\mathrm{Pt}$ DSSC is calculated and compared with Zno-DSSC without PhC.It is concluded that the presence of porous $1 \mathrm{D} \mathrm{SiO}_{2} / \mathrm{TiO}_{2} \mathrm{PhC}$ enhance the efficiency of $\mathrm{DSSC}$. 


\section{Construction of DSSC}

The DSSC structure comprised by FTO, ZnO photoelectrode, N719 dye, KI electrolyte solution with platinum counter electrode was theoretical designed. Probably, DSSCs are usually built with two layers of conductive transparent media that allow a medium to deposit the semiconductor and catalyst. Here the porous $\mathrm{ZnO}$ nano-particle semiconductor film is deposited on transparent conducting oxide (TCO)-coated glass substrate which act as a photo electrode and Platinum deposited TCO serves as a counter electrode respectively [21]. The N719 dye is the component of DSSC responsible for the maximum absorption. It is anchored to the $\mathrm{ZnO}$ nano-particle surface with liquid $\mathrm{KI}$ electrolyte. Redox couple should be able to regenerate the oxidized dye efficiently.Both operating $\mathrm{ZnO}$ and $\mathrm{Pt}$ counter electrodes are bound together, and an electrolyte $\mathrm{KI}$ is then loaded with aid of a syringe._Counter electrode catalyzes the reduction of $\mathrm{I}^{-} / \mathrm{I}^{-3}$ liquid electrolyte and gathers holes from the hole transport material. The figure 1 shows the schematic structure of $\mathrm{ZnO}-\mathrm{Pt}$ DSSC.

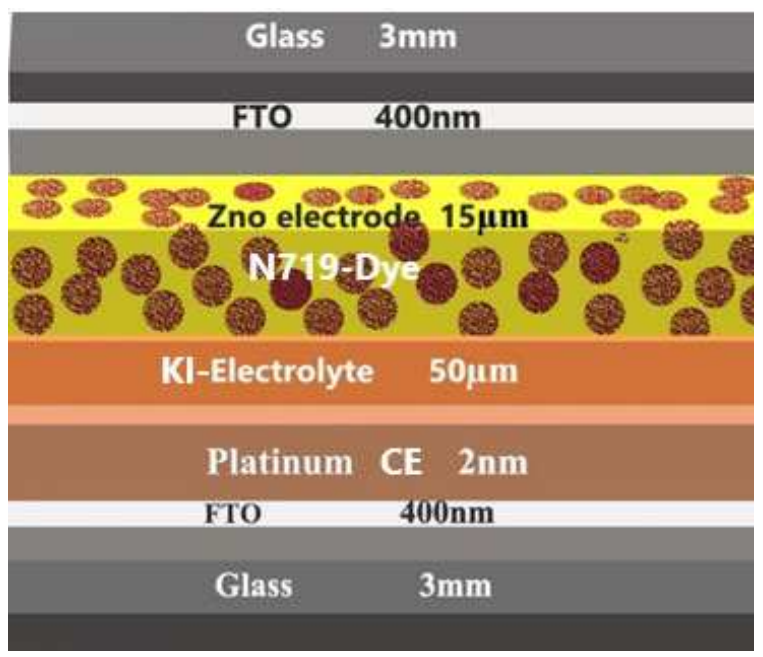

Fig.1.Schematic Structure of the designed DSSC

\section{Optical Properties of $\mathrm{ZnO}$ working electrode}

The optical properties of the N719 loaded ZnO working electrode are essential to evaluate the absorption of the entire structure of the $\mathrm{ZnO}$ DSSC with and without $1 \mathrm{D} \mathrm{PhC}$. From the recent literature of experimental research, the estimated absorbance values of the $\mathrm{N} 719$ loaded $\mathrm{ZnO}$ working electrode is found to be $34.28 \%$ for a wavelength of $534 \mathrm{~nm}$ having the electrode thickness of $330 \mathrm{~nm}$ [22].

The refractive index of $\mathrm{N} 719$ loaded $\mathrm{ZnO}$ working electrode is calculated from the following equation [24]. 


$$
n=\frac{1+R+\sqrt{R}}{1-R}
$$

The calculated refractive index of $\mathrm{N} 719$ loaded $\mathrm{ZnO}$ working electrode is comparable with various experimental work [25].

The reflectance is calculated from the following equation

$$
R=1-(A+T)
$$

The transmission of Dyed $\mathrm{ZnO}$ is calculated from the absorbance using Beer's lambert law [23].

Table:1. Refractive index and thickness of different layers of ZnO-Pt DSSC device with 1D PhC coupled layer for the wavelength range $(400-900 \mathrm{~nm})[22]$.

\begin{tabular}{|l|l|l|l|}
\hline Layers & Components & $\begin{array}{l}\text { Refractive } \\
\text { index }\end{array}$ & Thickness \\
\hline 1 & Substrate(glass) & 1.5 & $3 \mathrm{~mm}$ \\
\hline 2 & FTO & 1.81 & $400 \mathrm{~nm}(400-600 \mathrm{~nm})$ \\
\hline 3 & Dyed $\mathrm{ZnO}$ & 1.94 & $15 \mu \mathrm{m}$ \\
\hline 4 & Dye $/ \mathrm{SiO}_{2} / \mathrm{KI}$ & 1.43 & $95 \mathrm{~nm}$ \\
\hline 5 & Dye $/ \mathrm{TiO}_{2} / \mathrm{KI}$ & 1.81 & $88 \mathrm{~nm}$ \\
\hline 6 & Electrolyte & 1.42 & $50 \mu \mathrm{m}$ \\
\hline 7 & Platinum & 2.32 & $2 \mathrm{~nm}$ \\
\hline 8 & FTO & 1.81 & $400 \mathrm{~nm}$ \\
\hline 9 & Substrate(glass) & 1.5 & $3 \mathrm{~mm}$ \\
\hline
\end{tabular}

DSSC consists of multiple thin layers with distinct optical properties. The conventional optical TMM is used in this work to calculate the distribution of light intensity in DSSC [25]. A classical interaction exists between the electromagnetic radiation and a finite onedimensional non-periodic multilayer, where the corresponding Maxwell's equations are solved using TMM formalism. This interaction system fulfils the same conditions proposed by the reflection, transmission and absorption, within the layers, and optical interference between incoming and outgoing optical electric fields [26].

The index of refraction which may be expressed as $n_{j}(\lambda)=n_{j}(\lambda)+i k_{j}(\lambda)=n_{j}(\lambda)+i \lambda \alpha_{j}(\lambda) / 4 \pi$ and thickness $\mathrm{dj}$ for each layer $\mathrm{j}$. Here $\mathrm{nj}$ is the real refractive index, $\mathrm{k}_{\mathrm{j}}$ is the imaginary refractive index, and $\alpha_{j}$ is the absorption coefficient $j=1,2 \ldots m$, the figure 1 shows the theoretically designed DSSC with actual parameters of different layers. Light of intensity $\mathrm{I}_{0}$ is 
assumed to be incident normal to the substrate for a centre wave length of $550 \mathrm{~nm}\left(\lambda_{0}\right)$ and multiple reflections at the air/substrate and substrate/ multilayer interfaces are taken into account for the study of transmission spectra of DSSC [27].

\section{Integration of 1D Photonic crystal in DSSC}

By employing multilayers made of photonic crystal with multilayers having different lattice parameters is fabricated that possible to increase the photogenerated current for the whole spectral region in which the dye absorbs. Hence the presence of photonic crystal inside the ZnO-Pt DSSC enhance the light harvesting efficiency. In this section, we numerically analyse the integrate system of the $\mathrm{ZnO}-\mathrm{Pt}$ DSSC with $1 \mathrm{D}$ porous $\mathrm{SiO}_{2} / \mathrm{TiO}_{2}$ photonic crystals shown in figure 2. Initially the optical properties of ZnO-Pt DSSC structure are analyzed using TMM method. Secondly the optical properties of $1 \mathrm{D}$ porous $\mathrm{SiO}_{2} / \mathrm{TiO}_{2}$ photonic crystals coupled $\mathrm{ZnO}-\mathrm{Pt}$ DSSC are calculated. The $\mathrm{PhC}$ structure consist of alternative porous $\mathrm{SiO}_{2}$ and $\mathrm{TiO}_{2}$ dielectric layers, whose optical parameters are taken from the literature [28,29]. The thickness of $\mathrm{SiO}_{2} / \mathrm{TiO}_{2}$ layers are taken as $d_{\mathrm{Sio} 2}=95 \mathrm{~nm}$ and $\mathrm{d}_{\mathrm{Tio} 2}=80 \mathrm{~nm}$. The figure (2) shows that the porous $1 \mathrm{D} \mathrm{SiO}_{2} / \mathrm{TiO}_{2} \mathrm{PhC}$ coupled DSSC.

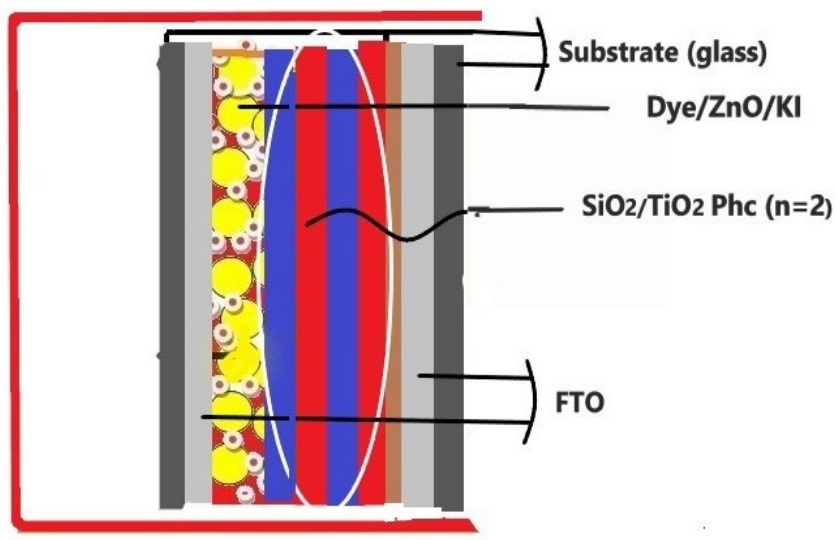

Fig.2.Schematic Structure of the 1D $\mathrm{SiO}_{2} / \mathrm{TiO}_{2} \mathrm{PhC}$ coupled DSSC

The matrices are formed for the intersection between two layers and wave propagation through each layer. The product of all the transfer matrices forms the actual transfer-matrix of solar cell. The photon absorption of these two solar cell designs (with and without $\mathrm{PhC}$ ) has been favorably compared with the state-of-art solar cell designs. The combination of sub cell layers has yielded very high photon absorption through the entire solar radiation spectrum. The layers can represent in a matrix form in which the product of the individual layers are matrices [7]. Finally, this method involves the system converting the matrix into reflection, transmission and absorption coefficient [31].

According to TMM, each single layer has a transfer matrix the M is given by [7-8]. 
$140 \quad M=\left[\begin{array}{ll}m_{11} & m_{12} \\ m_{21} & m_{22}\end{array}\right]=\left[\begin{array}{ll}\cos \delta & \frac{i}{\gamma_{l}} \sin \delta \\ i \gamma_{1} \sin \delta & \cos \delta\end{array}\right]$

141 The phase difference is $\delta=\left(\frac{2 \pi}{\lambda_{0}}\right) \times \gamma \times t \times \cos (\theta)$

$\lambda_{0}$-Centre wavelength, $t$-Thickness of incident layer, $\gamma$-refractive index of layer

The product of each intermediate layer starting with air layer, the resulting products describes entire stack in the order in which lights encounter them. Since each layer associated with its own transfer matrix, for our theoretically designed photonic crystal based DSSC system, the matrix describing the number of layers between the air and substrate according to Macleod et.al is given by

$$
M_{\text {total }}=M_{1} * M_{2} * M_{3} * M_{4} * \mathrm{M}_{5} *\left(\mathrm{M}_{\mathrm{H}} * \mathrm{M}_{\mathrm{L}}\right)^{N} * \mathrm{M}_{6} * \mathrm{M}_{7} * \mathrm{M}_{8}
$$

$\mathrm{M}_{1}, \mathrm{M}_{2}, \mathrm{M}_{3}, \mathrm{M}_{4}, \mathrm{M}_{5}, \mathrm{M}_{6}, \mathrm{M}_{7}, \mathrm{M}_{8}$ are glass substrate, FTO, ZnO, Dye, electrolyte, platinum, FTO and glass substrate respectively.

$\mathrm{M}_{\mathrm{H}}$ and $\mathrm{M}_{\mathrm{L}}$ are the corresponding components of the porous $\mathrm{SiO}_{2} / \mathrm{TiO}_{2}$ photonic crystal and $\mathrm{N}$ is the period of photonic crystal.

$$
\left.\left(M_{H} M_{L}\right)^{N}=\left(\left[\begin{array}{ll}
\cos \delta_{H} & \frac{i}{\gamma_{H}} \sin \delta_{H} \\
i \gamma_{H} \sin \delta_{H} & \cos \delta_{H}
\end{array}\right] \times\left[\begin{array}{ll}
\cos \delta_{L} & \frac{i}{\gamma_{L}} \sin \delta_{L} \\
i_{\gamma_{L}} \sin \delta_{L} & \cos \delta_{L}
\end{array}\right]\right)\right)^{N}
$$

For the entire structure of photonic crystal based DSSC, the total transfer matrix is given by

$$
M_{\text {total }}=\left[\begin{array}{ll}
m_{11} & m_{12} \\
m_{21} & m_{22}
\end{array}\right]
$$

where the matrix elements can be achieved in terms of the elements of the single-period matrix.

From the total matrix, the transmission coefficient,transmittivity $\mathrm{T}$, reflection coefficient $\rho$, reflectivity $\mathrm{R}$ and absorptivity $\mathrm{A}$ can be found. To define $\mathrm{R}, \mathrm{T}$, and $\mathrm{A}$, the reflection coefficient is

$$
\rho=\frac{\gamma_{0} m_{11}+\gamma_{0} \gamma_{s} m_{12}-m_{21}-\gamma_{s} m_{22}}{\gamma_{0} m_{11}+\gamma_{0} \gamma_{s} m_{12}+m_{21}+\gamma_{s} m_{22}}
$$

$$
R=\rho \times \rho^{*}
$$

Where the asterisk denotes the complex conjugate 
The reflection coefficiencts is

165

166

167 The transmittivity is

$$
\tau=\frac{2 \gamma_{0}}{\gamma_{0} m_{11}+\gamma_{0} \gamma_{s} m_{12}+m_{21}+\gamma_{s} m_{22}}
$$

168

168

\section{Calculated photovoltaic properties of $1 \mathrm{D} \mathrm{SiO}_{2} / \mathrm{TiO}_{2} \mathrm{PhC}$ coupled ZnO-Pt DSSC}

177 In this work the photocurrent density $\left(\mathrm{J}_{\mathrm{ph}}\right)$, voltage $\left(\mathrm{V}_{\mathrm{oc}}\right)$, saturation $\operatorname{current}\left(\mathrm{J}_{0}\right)$, quantum 178

$$
J_{p h}=e \int_{\lambda_{\min }}^{\lambda_{\max }} A^{*} \phi_{T}(\lambda) \mathrm{d} \lambda
$$

where e-electronch $\arg e, A-$ Total absorbtion of Zno-Pt DSSC calculated from [24]

$$
\varphi_{T}=\frac{p_{\text {in }}}{w_{p h}}=\frac{1000}{509 \times 10^{-21}}=1.96 \times 10^{21} \mathrm{~m}^{-2} \mathrm{~s}^{-1}
$$

$w_{p h}=h^{*} f_{g} \& p_{\text {in }}$-incident flux at solar spectrum A.M 1.5 is $1000 \mathrm{~W} / \mathrm{m}^{2}$

$$
f_{g}=q W_{g} / h
$$

where $W_{g}$ is the bandgap of $\mathrm{ZnO}$ is $3.37 \mathrm{eV}$ 


$$
V_{\text {OC }}=\frac{K T}{e} \ln \left(\frac{\mathrm{J}_{p h}}{J_{0}}+1\right)
$$

$$
J_{p h} \text { calculated from equation (10) }
$$

$$
\begin{gathered}
J_{0}=-2 e \pi \int_{0}^{\lambda_{g}} \frac{2 h c^{2}}{\lambda^{5}}\left[\exp \left(\frac{h c}{\lambda K_{B} \mathrm{~T}}\right)-1\right]^{-1} \mathrm{~d} \lambda \\
\mathrm{h}=\text { planck's constant, } \mathrm{c}=\text { velocity of light, }\left[\exp \left(\frac{h c}{\lambda K_{B} \mathrm{~T}}\right)-1\right] \square-1
\end{gathered}
$$

The fill factor may be calculated [31] using the equation

$$
F F=\frac{v_{o c}-\ln \left(v_{o c}+0.72\right)}{v_{o c}+1}
$$

$$
\text { where } v_{o c}=e V_{o c} / k T
$$

The efficiencies of the theoretical designed DSSC with and without PhC may be calculated using the equation

$$
\eta=\frac{J_{p h} * V_{o c} * F F}{P_{i n}}
$$

\section{Results and Discussions}

The optical parameters such as transmittance, absorptance and reflectance of the DSSC with and without PhC can be calculated using TMM method, by solving the equations (7) to

\begin{tabular}{|c|c|c|c|c|c|c|c|c|c|}
\hline \multirow{3}{*}{$\begin{array}{l}\text { Wavelength } \\
(\mathrm{nm})\end{array}$} & \multicolumn{9}{|c|}{ ZnO-Pt DSSC } \\
\hline & \multicolumn{2}{|c|}{ without PhC } & \multicolumn{4}{|c|}{$\mathrm{n}=2\left(\mathrm{SiO}_{2} / \mathrm{TiO}_{2}\right)$} & \multicolumn{3}{|c|}{$\mathrm{n}=3\left(\mathrm{SiO}_{2} / \mathrm{TiO}_{2}\right)$} \\
\hline & $\mathbf{T}$ & $\mathbf{A}$ & $\mathbf{R}$ & $\mathbf{T}$ & $\mathbf{A}$ & $\mathbf{R}$ & $\mathbf{T}$ & $\mathbf{A}$ & $\mathbf{R}$ \\
\hline 300 & 0.94 & 0.02 & 0.04 & 0.94 & 0.04 & 0.02 & 0.9 & 0.04 & 0.06 \\
\hline 400 & 0.77 & 0.0038 & 0.23 & 0.8 & 0.04 & 0.17 & 0.94 & 0.01 & 0.04 \\
\hline 500 & 0.94 & 0.01 & 0.17 & 0.65 & 0.02 & 0.33 & 0.45 & 0.01 & 0.54 \\
\hline 600 & 0.93 & 0.02 & 0.05 & 0.52 & 0.01 & 0.47 & 0.35 & 0.01 & 0.64 \\
\hline 700 & 0.92 & 0.02 & 0.07 & 0.45 & 0.07 & 0.48 & 0.39 & 0.03 & 0.58 \\
\hline 800 & 0.85 & 0.02 & 0.13 & 0.84 & 0.01 & 0.15 & 0.89 & 0.02 & 0.1 \\
\hline 900 & 0.63 & 0.01 & 0.36 & 0.82 & 0.02 & 0.16 & 0.88 & 0.06 & 0.06 \\
\hline
\end{tabular}
(12) with MATLAB software. The values are calculated and tabulated in the given table 2

Table .2. Transmittivity (T), Absorptivity (A) and Reflectivity (R) measurement of ZnO-Pt DSSC coupled with and without $1 \mathrm{D} \mathrm{SiO}_{2} / \mathrm{TiO}_{2} \mathrm{PhC}$ 
Table 2 indicates that the transmittance, absorptance and reflectance with the different periods $(\mathrm{n}=0,2,3)$ of $1 \mathrm{D} \mathrm{SiO}_{2} / \mathrm{TiO}_{2} \mathrm{PhC}$ coupled $\mathrm{ZnO}-\mathrm{Pt} \mathrm{DSSC}$ configuration. Figure 3 shows the optical characteristics of $\mathrm{ZnO}-\mathrm{Pt}$ DSSC with $1 \mathrm{D} \mathrm{SiO}_{2} / \mathrm{TiO}_{2} \mathrm{PhC}$ coupled layers( $\left.\mathrm{n}=0,2,3\right)$. The effect is more pronounced in the range of $500 \mathrm{~nm}-800 \mathrm{~nm}$. In table 1 the Absorptivity result indicates that the photo electrode does not consume incident light in a single pass owing to the low light scattering of the multilayer non-periodic structure. But the presence of $1 \mathrm{D} \mathrm{SiO}_{2} / \mathrm{TiO}_{2}$ $\mathrm{PhC}$ coupled inside near the working electrode can be form the scttering centres and strengthen the scattering process by its periodic structure. Light scattering is employed in dye-sensitized solar cells to improve the optical absorption of the incident light [32].
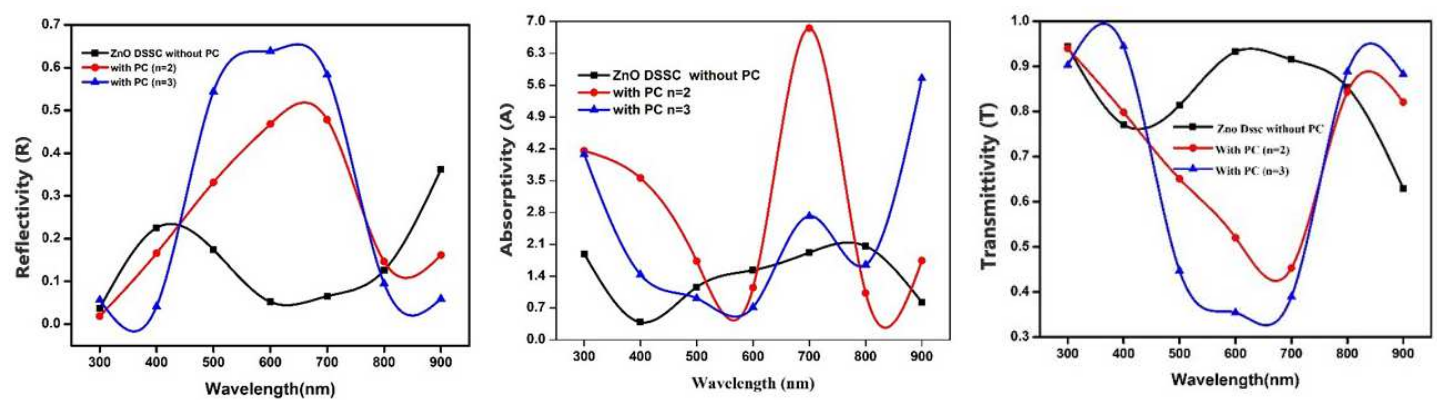

Figure. 3 The reflectance, absorptance and transmittance profile of ZnO-Pt DSSC coupled with and without $1 \mathrm{D} \mathrm{SiO}_{2} / \mathrm{TiO}_{2} \mathrm{PhC}$

From the absorbtion graph it is understood that more absorbtion takes place when DSSC is coupled with $\mathrm{PhC}$. It gets maximum absorption of light inDSSC with $\mathrm{PhC}$ having period $\mathrm{n}=2$ compared with $\mathrm{PhC}$ having period $\mathrm{n}=2$.It may due to the refractive index contrast make a disorder in the interface of PhC layers. The optimized periods of layers can increase the path length as well as diffused or multiple scattered/reflected and localized the incident light at longer time. As a result, significant optical absorption amplification in a broad spectral range occurs in structures that combine the presence of a 1D photonic crystal and a multi-layer of non-periodically structured absorbing material.

The Photo current density, open circuit voltage for $1 \mathrm{D} \mathrm{SiO}_{2} / \mathrm{TiO}_{2} \mathrm{PhC}$ integrated $\mathrm{ZnO}-\mathrm{Pt}$ DSSC are analysed using equation (13)\&(14). The effect is maximum when the DSSC coupled with 1D $\mathrm{PhC}$ with period $\mathrm{n}=2$. The effect of Photo current density with number of period of $\mathrm{PhC}$ layers is studied and is shown in the figure (4). The short-circuit current increases with the number of period with two. 

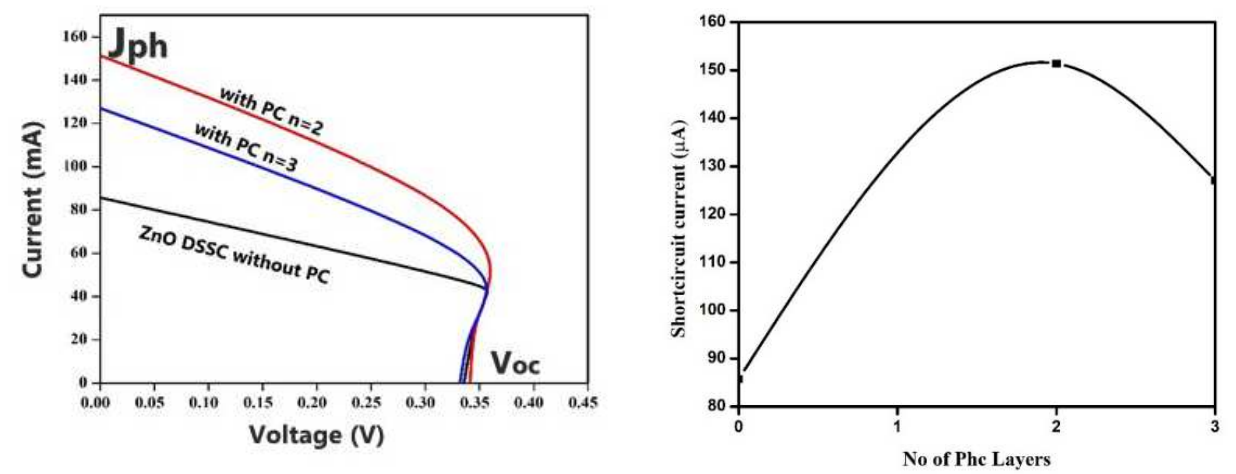

\section{Figure.4. I-V curve and Photo current -vs number of periods of ZnO-Pt DSSC coupled with and without $1 \mathrm{D} \mathrm{SiO}_{2} / \mathrm{TiO}_{2} \mathrm{PhC}$}

Because of the increase of optical absorption by multiple reflection / scattering in the interface of $\mathrm{PhC}$ structure, it can localize the maximum number of photons on the electrode therefore the short-circuit current is increased in the DSSC. The 1D PhC act as absorber or bottom reflector can trap the incident light. It reduces the group velocity of the photons which can prevent recombination of the excitons for a longer time, hence it leads to the higher rate of photoelectron generation. The lowering of short-circuit current after $n=2$ is due to the maximum reflection in the forbidden bandgap of $\mathrm{PhC}$. By analysing all the optical parameters and substituted in equation (26), the efficiency of DSSC may be investigated. The calculated $\mathrm{J}_{\mathrm{sc}}, \mathrm{V}_{\mathrm{oc}}, \mathrm{FF}$ and $\eta$ for different number of periods in the $\mathrm{PhC}$ are shown in the table 3 . It is concluded that the DSSC having $\mathrm{PhC}$ with period of $\mathrm{n}=2$ get a maximum value of $4.5 \%$.

Table. 3 photovoltaic parameters of $\mathrm{ZnO}$-Pt DSSC coupled with and without $1 \mathrm{D} \mathrm{SiO}_{2} / \mathrm{TiO}_{2}$ PhC

\begin{tabular}{|l|l|l|l|l|l|}
\hline $\begin{array}{l}\text { ZnO-Pt } \\
\text { DSSC }\end{array}$ & $\begin{array}{l}\text { Number } \\
\text { of } \\
\text { periods (n) }\end{array}$ & $\mathbf{J s c}\left(\boldsymbol{\mu A ~ \text { cm} ^ { - 2 } )}\right.$ & $\mathbf{V o c}(\mathbf{V})$ & FF & $\boldsymbol{\eta}(\%)$ \\
\hline $\mathrm{SiO}_{2} / \mathrm{TiO}_{2}$ & 0 & 85.71 & 0.37 & 0.75 & 2.3 \\
\cline { 2 - 6 }$(\mathrm{PhC})$ & 2 & 152 & 0.39 & 0.72 & 4.5 \\
\cline { 2 - 6 } & 3 & 127 & 0.38 & 0.76 & 3.7 \\
\hline
\end{tabular}

The theoretical results revealed the porous $1 \mathrm{D} \mathrm{SiO}_{2} / \mathrm{TiO}_{2} \mathrm{PhC}$ absorbing layer and act as a potential couple layer to improve the efficiency by trapped and initiate the photons drive gradually back through the absorbing electrode in the selective spectrum range 400nm -900nm.

\section{Conclusion}

The photovoltaic parameters of ZnO-Pt with N719 dye based DSSC are calculated and also $\mathrm{ZnO}-\mathrm{Pt}$ coupled with porous $1 \mathrm{D} \mathrm{SiO}_{2} / \mathrm{TiO}_{2} \mathrm{PhC}$ with different periods is theoretically designed and analyzed. The absorptance. of the integrated system of ZnO-Pt DSSC with and 
without $1 \mathrm{D} \mathrm{SiO}_{2} / \mathrm{TiO}_{2} \mathrm{PhC}$ are calculated using TMM method. It is found that the desired integrated system may enable to maximize the absorption in the selective spectrum region (400$900 \mathrm{~nm})$. The short circuit current $\left(\mathrm{J}_{\mathrm{sc}}\right)$, open circuit Voltage $\left(\mathrm{V}_{\mathrm{oc}}\right)$, Fill factor $(\mathrm{FF})$ and hence the efficiency $(\eta)$, are calculated theoretically. The maximum short circuit current $\left(\mathrm{J}_{\mathrm{sc}}\right)$ is found to be $440 \mu \mathrm{A} \mathrm{cm}^{-2}$ and hence the maximum efficiency achieved is $4.5 \%$. for a $1 \mathrm{D} \mathrm{SiO}_{2} / \mathrm{TiO}_{2}$ $\mathrm{PhC}$ with two number of periods. The optical design of $1 \mathrm{D} \mathrm{SiO}_{2} / \mathrm{TiO}_{2} \mathrm{PhC}$ absorbing layer enhance the cell efficiency without affecting kinetic balance between charge separation and recombination.

The authors declare that they do not have a conflict of interest

\section{FUNDING}

The study was carried out as part of under UGC-MANF scheme gran no.MANF-2018-19-TAM-90273

\section{ACKNOWLEDGEMENT}

The authors wish to express their sincere thanks to the DST-FIST PROGRAM - Arul Anandar College Karumathur.

\section{Author contributions:}

There are variety of methods available to increase the efficiency of DSSC. The propagation of light inside the DSSC can be controlled or modulated by the photonic crystals. Hence the photonic crystal embedded solar cell may be used to trap the light and hence to increase the efficiency of the solar cell.

\section{The problem being addressed:}

1D $\mathrm{SiO}_{2} / \mathrm{TiO}_{2}$ photonic crystal based ZnO-Pt DSSC with $\mathrm{N} 719$ dye is theoretically designed.The optical properties of theoretically designed DSSC such as transmittance, absorptance and reflectance are calculated. The use of $1 \mathrm{D} \mathrm{SiO}_{2} / \mathrm{TiO}_{2}$ photonic crystal light trapping structures in DSSCs demonstrates the ability to increase the performance of solar to electrical conversion.

\section{Compliance with ethical standards} form.

The submitted work should be original and should not have been published elsewhere in any

\section{Availability of data and material}

The [data type "Photonic structure parameters"] data that support the findings of this study are availablein[http://www.tandfonline.com/loi/tmop20,"][https://www.researchgate.net/publication/ 334045078]. 
281

282

283

284

285

286

287

288

289

290

291

292

293

294

295

296

297

298

299

300

301

302

303

304

305

306

307

\section{Reference}

[1] H.Tributsch,M.Calvin, Photochem\& Photobiol. 14:95 (1971).

[2] H.Tsubomura ,M.Matsumura Y.Nomura, T.Amamiya ,Nature. 261,403 (1976).

[3] Brian O'Regan, Michael Grätzel Nature. 353,737.(1991).

[4] M.Quintana,T. Edvinsson,A. Hagfeldt,G. Boschloo ,J. Phys. Chem. C, 111,1035 (2007)

[5] J.Kroon, et al. Prog. Photovoltaics.15, 1, (2007)

[6] I.K Ding,N. Tetreault,J. Brillet,B.E Hardin, E.H. Smith, S.J.Rosenthal, K.Sauvage, Sakoda Opt. Express. 4, 167 (1999)

[7] D.Mittleman,J. Bertone, P. Jiang,K. Hwang, V.J.Colvin,. Chem.Phys.111, 345(1999)

[8] R.Rengarajan, D.Mittleman, C. Rich, V.Colvin, Phys. Rev. E 71,15976(2005).

[9] A.Mihi, H.J M1'guez, H. J. Phys. Chem. B 109, 15968 (2005).

[10] S.Hore,C. Vetter, R. Kern, H.Smit, A.Hinsch, A. Sol. Energy Mater. Sol. Cells. 90, 1176 (2006).

[11] J.Ferber,J. Luther, Sol. Energy Mater. Sol. Cells. 54, 265 (1998).

[12] S. B. Mallick, N. P. Sergeant, M. Agrawal, J..Y. Lee and P. Peumans, MRS Bull.36, 453(2011).

[13] K. Vynck, M. Burresi, F. Riboli and D. S. Wiersma, Nat. Mater. 11, 1017 (2012).

[14] W. Hou, P. Pavaskar, Z. Liu, J. Theiss, M. Aykol and S. B. Cronin, Energy Environ. Sci. 4, 4650 (2011).

[15] E. T. Yu , J. van de Lagemaat, MRS Bull. 36, 424 (2012).

[16] M. A. Green, Prog. Photovoltaics: Res. Applications.17, 183 (2009).

[17] L. Kranz, S. Buecheler and A. N. Tiwari, Sol. Energy Mater. Sol. Cells.119, 278 (2013).

[18] S. Nishimura, N. Abrams, B. A. Lewis, L. I. Halaoui, T. E. Mallouk, K. D. Benkstein, J. van de Lagemaat and A. J. Frank, J. Am. Chem. Soc. 125, 6306 (2003). 
[19] J.A Anta, E. Guillén R.J.Tena-Zaera, Phy Chem C.11611413 (2012).

[20] Amrik Singh,Devendra Mohan2,Dharamvir Singh Ahlawat, Richa Processing and Application of Ceramics.11(3), 213 (2017)

[21] cF. Qiao, L. Dang, Q. Lu, and F. Gao, J.Phys.Chem C.118,(30) 16856(2014).

[22] Thomas G. Mayrhofer, Jürgen Popp, Acta Part A: Molecular and Biomolecular Spectroscopy. 215, 345 (2019).

[23] Jose Miguel Luque-Raigon,Janne Halme, Hernan Miguez, Journal of Quantitative Spectroscopy \& Radiative Transfer. 134 ,9(2014).

[24] Yeh P. Optical waves in layered media. Hoboken: Wiley-Interscience Publication 2005 [chapter 6]. ISBN: 978-0-471-73192-4

[25] M.David J.Huang, Henry Snaith, Michael Grätzel, Klaus Meerholz, and J.Adam J. Appl. Phys. 106, 073112 (2009)

[26] José Miguel Luque-Raigón,Janne Halme and Carmen López-LópezJ. Photon. Energy 9(2), 025501 (2019),

[27] Mohammed M. Shabat,Hala J. El-Khozondar,Ahmed A. AlShembari and Rifa J. ElKhozondar.Modern Physics Letters B. 32(28), 1850346 (2018).

[28] George Y.Margulis Brian E. Hardin, I-Kang Ding, Eric T. Hoke, and Michael D. McGehee. Adv. Energy Mater.3, 959-966 (2013)

[29] Ouarda Barkat, Badreddine Mamri Electric Electron Tech Open Acc J.2(2), 9 (2018)

[30] Zahraa Hummam Mohammed IOP Conf. Ser.: Mater. Sci. Eng. 518, 032026 (2019)

[31] Klaus Jäger,Olindo Isabella,Arno H.M. Smets,René A.C.M.M. van Swaaij and Miro ZemanSolar EnergyFundamentals, Technology, and Systems Delft University of Technology, 2014

[32] T. G. Deepak, G. S. Anjusree, Sara Thomas, T. A. Arun, Shantikumar V Nair, A. Sreekumaran Nair,RSC Advances,4,17514 (2014)

[33] Lucio Cinà,Babak Taheri, Andrea Reale and Aldo Di Carlo, Energies, 9, 686 (2016) 


\section{Figures}

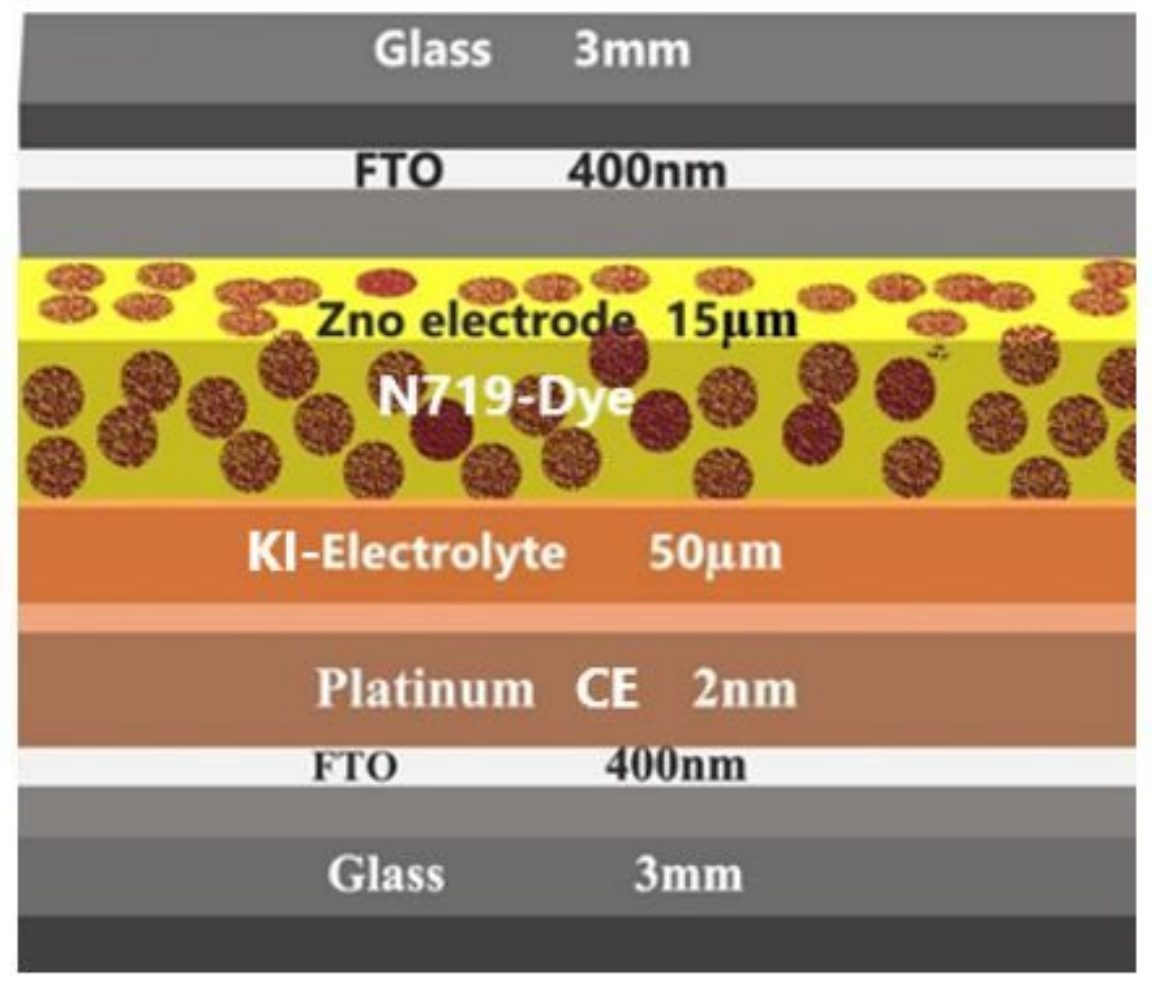

Figure 1

Schematic Structure of the designed DSSC

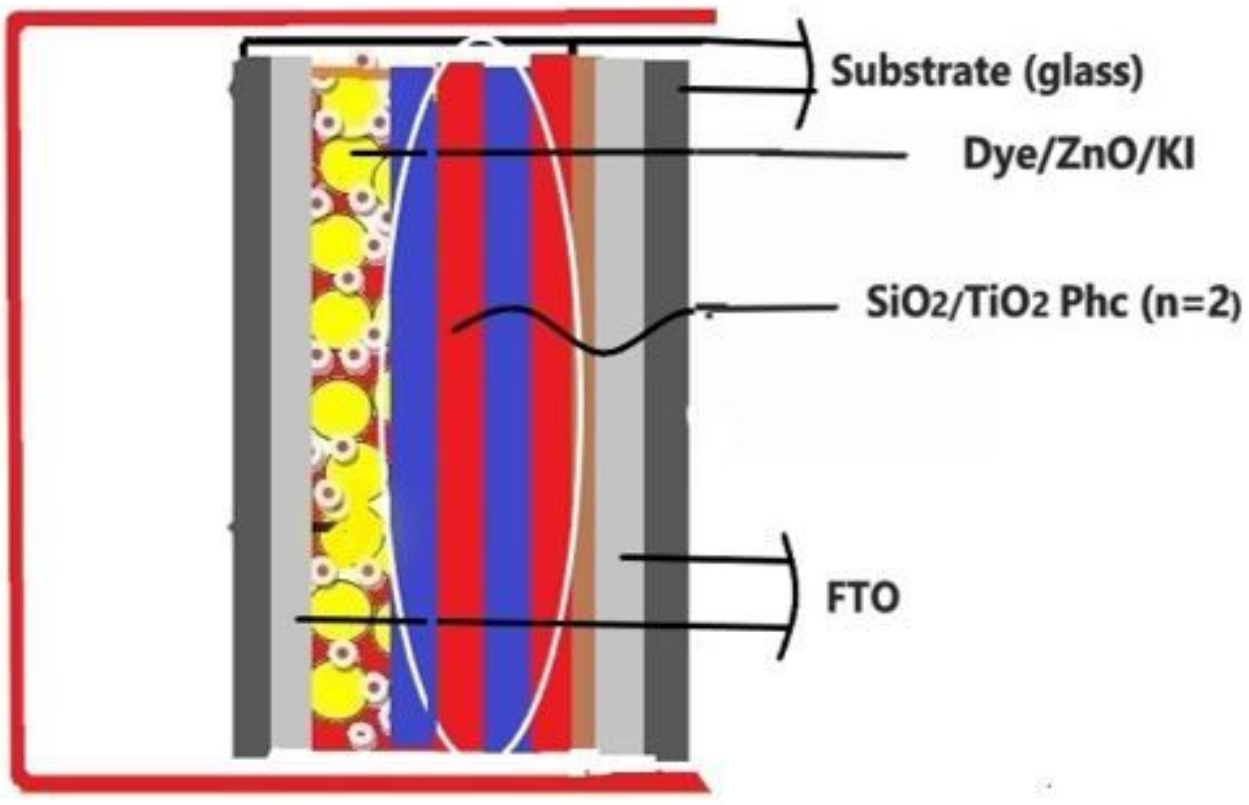

Figure 2

Schematic Structure of the 1D SiO2/TiO2 PhC coupled DSSC 

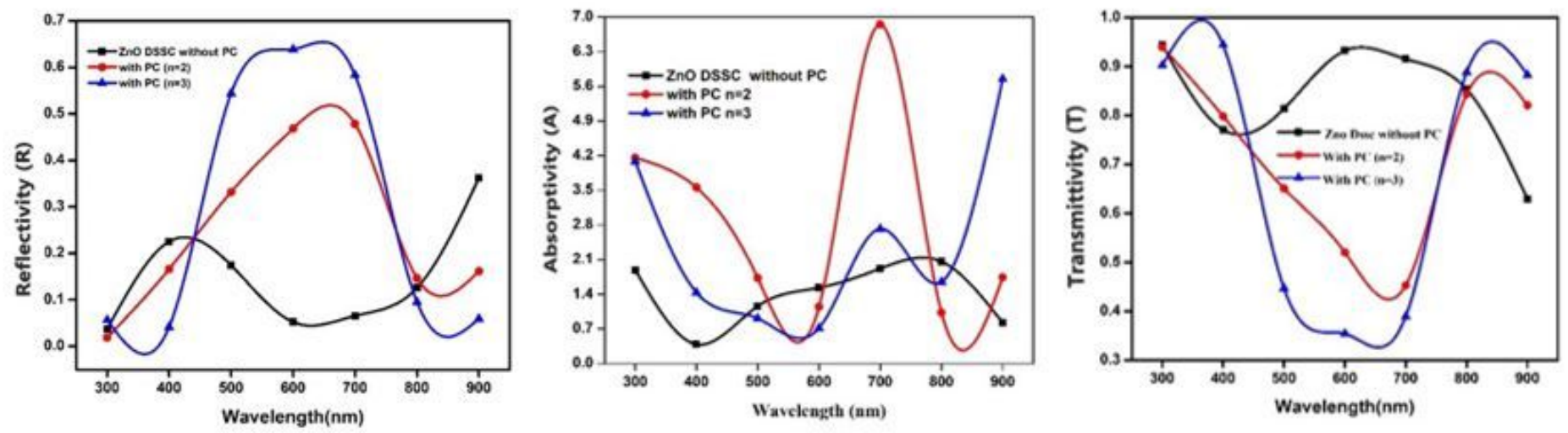

Figure 3

The reflectance, absorptance and transmittance profile of ZnO-Pt DSSC coupled with and without 1D $\mathrm{SiO} 2 / \mathrm{TiO} 2 \mathrm{PhC}$
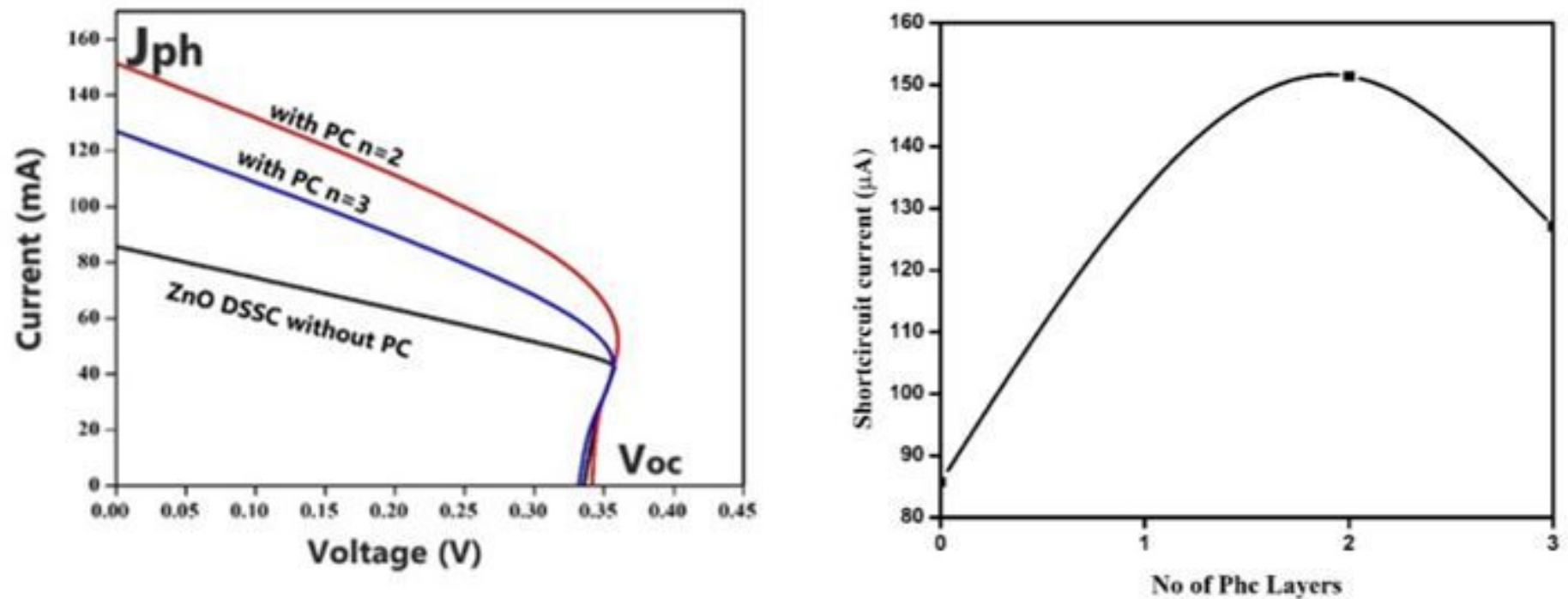

Figure 4

I-V curve and Photo current -vs number of periods of ZnO-Pt DSSC coupled with and without 1D $\mathrm{SiO} 2 / \mathrm{TiO} 2 \mathrm{PhC}$ 